\title{
Midazolam Increases The Risk of Delirium In Critically III Patients: A Propensity Score Analysis.
}

He-Jie Shi

Shenzhen People's Hospital

Rui-Xia Yuan

Shenzhen People's Hospital

Jun-Zhi Zhang

Shenzhen People's Hospital

Jia-Hui Chen

Shenzhen People's Hospital

An-Min Hu ( $\nabla$ anmin.edu@gmail.com )

Shenzhen People's Hospital https://orcid.org/0000-0002-6507-6423

\section{Research Article}

Keywords: Midazolam, Delirium, Critically ill patients, Propensity score analysis

Posted Date: December 30th, 2021

DOI: https://doi.org/10.21203/rs.3.rs-955292/v1

License: @ (i) This work is licensed under a Creative Commons Attribution 4.0 International License. Read Full License 


\section{Abstract}

BACKGROUND: Midazolam is commonly administered in the intensive care unit (ICU) because of its limited effect on hemodynamics and stable calming and sleep-induction effects. Recent concerns about an increased risk of delirium associated with midazolam have resulted in decreased midazolam usage in the ICU. However, whether midazolam administration within 24 hours prior is related to the occurrence of delirium is still unknown.

METHODS: We used real-world data from MIMIC III v1.4, MIMIC-IV v0.4 and elCU Collaborative Research to perform comparisons and assess the associated outcome effectiveness. We performed a systematic study with two cohorts to estimate the relative risks of outcomes among patients administered midazolam within 24 hours prior to delirium assessment. Propensity score matching was performed to generate a balanced 1:1 matched cohort and to identify potential prognostic factors. The outcomes included mortality, length of ICU stay, length of hospitalization, and odds of being discharged home.

RESULTS: Propensity matching successfully balanced covariates for 9,348 patients (4,674 per group). There was no significant difference in hospitalization duration, $(P=0.03)$. However, compared to no administration of midazolam, midazolam administration was associated with a significantly higher risk for delirium $(P<0.001)$. When compared with no midazolam administration, the use of midazolam, was associated with higher mortality and a longer ICU stay $(P<0.001)$. Patients treated with midazolam were relatively less likely to be discharged home $(P<0.001)$.

CONCLUSIONS: Compared with no administration of midazolam, midazolam administration was associated with a difference in the incidence of delirium, mortality, ICU stay and likelihood of being discharged home but was not associated with hospitalization duration. These data suggest that midazolam may not be the preferred sedative drug for patients at risk for delirium.

\section{Background}

Delirium is a syndrome characterized by the acute onset of cerebral dysfunction with a change or fluctuation in mental status, inattention, and either disorganized thinking or an altered level of consciousness [1-4]. Delirium in patients over the age of 65 years is estimated to cost more than $\$ 164$ billion per year in the US [5]. With the government considering limiting payments for delirium, aggressive effort is needed to reduce all factors contributing to this condition [6].

Midazolam is still frequently used for sedation because of its limited effect on hemodynamics and its short half-life [7-9], despite clinical practice guidelines describing that benzodiazepine use is a modifiable risk factor for delirium in critically ill adults with strong supporting evidence [10]. However, real-world evidence of the relative effectiveness of midazolam and its associations with delirium in critically ill patients is lacking.

Based on the common use of midazolam for sedation of intensive care unit (ICU) patients, we performed a retrospective, multicenter, observational cohort study to investigate the relationship between midazolam administration within 24 hours prior to delirium assessment and the incidence of delirium in the ICU patients and patient-centered outcomes. This systematic study might improve delirium prevention.

\section{Methods}

\section{Data source}

Study data were derived from three electronic databases. The Multiparameter Intelligent Monitoring in Intensive Care (MIMIC) III (version 1.4) database [11], the Medical Information Mart for Intensive Care (MIMIC) IV (version 0.4) database [12], and the elCU Collaborative Research Database [13] are maintained by the Laboratory for Computational Physiology at Massachusetts Institute of Technology.

Study population and stratification 
The study population included all patients who underwent delirium assessment after admission to the ICU. For patients with multiple positive values, we included only the first episode. If all of the assessment results were negative, we also selected only the first assessment. The relevant data for each patient were collected only once. Patients who received midazolam or not within 24 hours before the diagnosis of delirium were observed, Patients were enrolled into two cohorts: midazolam vs. no midazolam.

The inclusion criteria in this study were as follows: (1) for patients with multiple ICU stays, only the first ICU stay was eligible; (2) adults $\geq 18$ years of age at ICU admission; (3) ICU stay $\geq 24$ hours; and (4) delirium assessment.

Outcomes

The primary outcome was the odds of delirium, and secondary outcomes included hospital mortality, ICU length of stay, hospitalization duration, and discharge destination (home versus elsewhere).

\section{Data analysis}

Patient characteristics included age, sex, ethnicity, acute physiology and chronic health evaluation (APACHE) III score, Glasgow Coma Scale (GCS), mean blood pressure (MBP), respiratory rate, urine volume; hemoglobin, white blood cell count, alanine transaminase, glutamic oxaloacetic transaminase, albumin, blood urea nitrogen, creatinine, lactate, oxygenation index, mechanical ventilation, and hospital characteristics. The APACHE-III scoring system is designed to prospectively predict mortality in individual ICU patients [14]. Hospital characteristics, including ICU type, number of ICU beds, and teaching status, were defined according to the database.

Descriptive data are presented as the medians (25th to 75th percentiles) for continuous variables and frequencies (\%) for categorical variables. Categorical variables were compared between groups using the chi-square test. Unpaired t-tests or Kruskal-Wallis tests were used for continuous variables.

Propensity score generation, stratification by deciles, and 1:1 matching between groups were performed using the R package Match It [15]. A nonparsimonious regression model was used to produce a propensity score for the group with fewer patients using the patient characteristics described above. For the propensity-score analysis (our primary analysis), each patient in the group with fewer patients was matched to their nearest neighbor with a score within 0.001 . We chose to match the third decimal point (a caliper of 0.001 ) because this value is less than 0.02 SDs of the propensity score, which is a commonly suggested range. Estimating the propensity score using a logit model resulted in both reasonable matches and an appropriate overall sample size. The final models included the hospital as a random effect and all patient characteristics were used to calculate the propensity score. Additionally, multivariable regression modeling, including all the patient characteristics used to calculate the propensity score, was performed to confirm these findings (secondary analysis).

Missing data were imputed with the multivariate imputation by chain equations (MICE) method [16]. The amount of missing data was low. All analyses were performed using $\mathrm{R}$ version 4.0.3.

\section{Results}

A total of 46,428 ICU patients and 61,051 ICU admissions in the MIMIC-III database v1.4, 50,048 ICU patients and 69,619 ICU admissions in the MIMIC-IV database v0.4, and 177,863 ICU patients and 626,858 ICU admissions in the elCU Collaborative Research Database were available. Of these, a total of 621,189 sequential delirium assessment records were available. Finally, 78,364 patients were included in this study. We identified 22,159 (28.28\%) patients with positive records.

A total of 4,808 patients received midazolam within 24 hours of admission. Before propensity score matching, there were statistically significant differences in age and ethnicity in the stratified analyses between the midazolam and no midazolam group. Overall, compared with patients in the no midazolam group, patients in the midazolam group were less likely to be female (41.6 vs. 45.8\%; $P<0.001)$ and had a higher APACHE-III score (median [interquartile range], 51 [13-15] vs. 38 [28-52]; 
$P<0.001)$. However, patients who received midazolam had higher values of blood urea nitrogen (BUN) $(21$ [13-34] vs. 20 [15-29]; $P<0.001)$ and white blood cell count (WBC) (11.6 [8.1-15.2] vs. 11.3 [8.7-13.7]; $P<0.001)$ but lower values of mean blood pressure(MBP) (80.3 [71.3-91.7] vs. 85.4 [75.3-93.5]; $P<0.001)$, hemoglobin $(\mathrm{Hb})(10.7$ [9-11.7] vs. 10.9 [9.7-11.8]; $P<$ 0.001), alanine transaminase (ALT) (67.9 [23-100.9] vs. 74.1 [26-96.8]; $P<0.001)$, glutamic oxaloacetic transaminase (GOT) (90.6 [33-144.1] vs. 99.3 [31-136.8]; $P<0.001)$ and albumin (3.1 [2.8-3.4] vs. 3.3 [3-3.5]; $P<0.001)$ than those who did not receive midazolam. Moreover, patients in the midazolam group had higher rates of mechanical ventilation $(65.2$ vs. $18.4 \%$; $P<$ $0.001)$ and a higher oxygenation index (54.7 [50-60.4] vs. 51.9 [50.6-57.3]; $P<0.001)$ than those in the no midazolam group (Table 1).

Propensity-matched analysis

After propensity matching, $97 \%$ of patients in the midazolam group were successfully matched $1: 1$ with an equal number of patients in the no midazolam group, yielding a total of 4,674 patients in each group. Propensity matching eliminated differences between patients and clinical variables and reduced differences in hospital characteristics. After matching, the baseline characteristics were balanced, as shown in Table 1.

In the fully adjusted, propensity score-matched cohorts, patients treated with midazolam exhibited a significant difference in odds of delirium (odds ratio [OR],2.54; 95\% confidence interval [Cl], 2.31-2.79; $P<0.001$ ) compared with patients who were not treated with midazolam. Moreover, patients who used midazolam had higher odds of mortality $(\mathrm{OR}, 1.33 ; 95 \% \mathrm{Cl}, 1.17-1.52 ; P$ $<0.001)$, more ICU days $(0.37 ; 95 \% \mathrm{Cl}, 0.29-0.45 ; P<0.001)$, and lower odds of being discharged home $(0 \mathrm{R}, 0.81 ; 95 \% \mathrm{Cl}$, $0.74-0.89 ; P<0.001)$ than patients who did not use midazolam. However, there were no significant differences in hospital length of stay between the two groups (Table 2).

Multivariable analysis

The entire cohort (78,364 patients) was then analyzed using multivariable regression after adjusting for differences in the patient and hospital characteristics used to calculate the propensity score. This multivariable analysis demonstrated that patients treated with midazolam exhibited significant differences in the odds of delirium (OR, 3.04; 95\% $\mathrm{Cl}, 2.83-3.26$; $P<$ $0.001)$ and mortality rate $(\mathrm{OR}, 1.30 ; 95 \% \mathrm{Cl}, 1.18-1.43 ; P<0.001)$ compared with patients who were not treated with midazolam. However, patients treated with midazolam had longer ICU stays $(0.54 ; 95 \% \mathrm{Cl}, 0.50-0.57 ; P<0.001)$ but similar hospital days $(-0.03 ; 95 \% \mathrm{Cl},-0.30$ to $0.23 ; P=0.81)$ than patients who were not treated with midazolam. Finally, patients who were not treated with midazolam had an increased likelihood of being discharged home than patients treated with midazolam $(0.79 ; 95 \% \mathrm{Cl}, 0.73-0.84 ; P<0.001)$ (Table 2).

\section{Discussion}

Using three large databases, MIMIC III v1.4, MIMIC-IV v0.4 and eICU Collaborative Research, we performed a multicenter, observational cohort study to assess outcomes in patients at risk for delirium who were treated with midazolam infusions within 24 hours before delirium diagnoses were defined. We observed that delirium was diagnosed in $28.28 \%$ of the patients, and patients who used midazolam within 24 hours before diagnosis were more likely to develop delirium. Moreover, our data show that midazolam was associated with multiple detrimental outcomes including an increased risk of mortality, longer ICU stays and lower likelihood of being discharged to home. However, there was no significant association between treatment with midazolam and length of hospitalization.

Recently, published meta-analyses have demonstrated that midazolam was associated with a significantly higher rate of delirium $[17,18]$. These studies were limited by small sample sizes and limited long-term observations. Another propensity score-matched cohort study showed that midazolam-dominant sedation strategies were associated with increased delirium risk, mortality, ICU length of stay and hospital days [19]; unfortunately, they did not test the isolated effects of midazolam and eliminate the influence of midazolam metabolism and clearance, while our study did. Additionally, a single-center analysis showed that benzodiazepine administration in an awake patient without delirium was associated with an increased risk of

Page $4 / 12$ 
delirium the next day [20]. However, a multicenter systematic comparison of the effectiveness and safety of midazolam within 24 hours prior to delirium assessment in ICU patients has been lacking.

There are multiple mechanisms by which midazolam may increase delirium. Midazolam activates $Y$-aminobutyric acid $A$ $\left(G_{A B A_{A}}\right)$ neuronal receptors in the brain, and their activation can alter the levels of numerous neurotransmitters, such as dopamine, serotonin, acetylcholine, norepinephrine, and glutamate, which are believed to be deliriogenic [21-23]. Midazolam could indeed be involved in delirium pathogenesis through overstimulation of the cortical GABA system, thereby reducing corticostriatal glutamatergic tone and ultimately hampering the filtering action of the thalamus, leading to confusion or psychosis [24]. In addition to altering neurotransmitter concentrations, midazolam may generate more central nervous system inhibitory effects at higher doses [25] and impair the quality of sleep via slow-wave sleep suppression, thus, possibly contributing to delirium $[23,26]$. Moreover, a recent animal study demonstrated that midazolam or inflammation, which downregulate brain PER2 levels, led to significant hippocampus-dependent cognitive deficits, as observed in some types of delirium [27], The hippocampus appears to play a critical role in the pathogenesis of delirium in humans [28].Furthermore, midazolam alters sleep patterns and increases the risk of circadian disruption and delirium in humans [29, 30].

Delirium may increase mortality, which is not directly related to midazolam administration. Midazolam use was found to be a risk factor for delirium after liver transplantation in a systematic review and meta-analysis, which also showed that delirium was a mortality risk factor according to the pooled results of ICU mortality [18]. Similarly, a multicenter, retrospective, cohort study by Lonardo et al demonstrated higher mortality in patients managed with benzodiazepines compared with those administered propofol. They postulated that midazolam's mortality effect might be due to increased rates of delirium [31], and some evidence supports that delirium is associated with substantial morbidity both during and after ICU admission [32-34]. Each additional day of delirium increases the hazard of mortality by $10 \%$ and increases the likelihood of a poor functional status at 3 and 6 months [35-38].

Our study has three strengths. First, this retrospective cohort study included a relatively large population and accurately measured clinical variables in an actual clinical setting in a large number of ICUs. Acknowledging the possibility of confounding, we used propensity score matched analysis to balance measured pretreatment variables that may influence the effect and impact the outcomes. Second, it is important to use time-dependent multivariable analysis methods given that disease severity, midazolam administration, and delirium occurrence frequently oscillate over the course of the ICU stay. We ensured that medical treatment was provided within 24 hours before the delirium assessment to limit the influence of other confounding factors. Third, this study used data from multiple ICU databases across a range of hospital and ICU settings, which made our results accurately reflect the outcomes seen in an actual practice environment.

Several limitations of this study warrant discussion. First, this is an observational study, and thus, causal associations cannot be determined. Second, there were some missing data for multiple confounding variables, and some variables, such as drug doses, target sedation levels, treatment durations or daily data on sedation levels, could not be effectively merged or compared. Bias may still exist despite the use of propensity score matching and regression modeling to control for a variety of patient and hospital confounders. Third, we could not exclude, measure, or control for the use of intermittent midazolam dosing given on an as-needed basis. We could exclude only those patients who were administered other sedative drugs, such as opioid drugs or propofol, to ensure that they received the same medication. Fourth, our study was a retrospective cohort study based on electronic healthcare records, and the data were generated during routine clinical visits. Since the MIMIC-III data ranged from 2001 to 2015, elCU Collaborative Research data ranged from 2014-2015 and MIMIC- IV data ranged from 2018-2019, our results were adjusted for the admission period.

\section{Conclusion}

Patients who used midazolam within 24 hours before the diagnosis of delirium were more susceptible to developing delirium, and they had higher odds of mortality, more ICU days, and lower odds of discharge to home than those who were not treated with midazolam. Therefore, we suggest that clinicians avoid administering midazolam to patients who are scheduled to be 
admitted to the ICU. Further studies are needed to evaluate the mechanism underlying these differences and to validate these findings in other cohorts of patients.

\section{Abbreviations}

ICU intensive care unit

MIMIC-III Multiparameter Intelligent Monitoring in Intensive Care III

MIMIC-IV Medical Information Mart for Intensive Care IV

APACHE-III Acute Physiology and Chronic Health Evaluation III

GCS Glasgow Coma Scale

MBP Mean Blood Pressure

MICE Multivariate Imputation by Chain Equations

BUN Blood Urea Nitrogen

WBC White Blood Cell

$\mathrm{Hb}$ hemoglobin

ALT Alanine Transaminase

GOT Glutamic Oxaloacetic Transaminase

OR Odds Ratio

Cl Confidence Interval

$\mathrm{GABA}_{\mathrm{A}}$ Y-aminobutyric Acid A

\section{Declarations}

ETHICS STATEMENT

Consent was obtained for the original data collection and the institutional review boards of the Massachusetts Institute of Technology (Cambridge, MA, USA) approved the establishment of the database. Therefore, the ethical approval statement and informed consent were waived for this manuscript.

\section{DATA AVAILABILITY STATEMENT}

The three databases used in this research, MIMIC-III, MIMIC IV and eICU are available for access, in part or in total, by relevant parties subject to abiding by their usage policies. To facilitate the reproduction of our results, we shall make fully anonymized data available on the figshare from the publication of this manuscript(https://figshare.com/s/6ffd470721a04b7b9ca3). Additionally, interested researcher can contact Mr. Hu email (anmin.edu@gmail.com) for more detailed information.

COMPETING INTERESTS

The authors declare that they have no competing interests.

FUNDING 
Dr. Hu received funding from Guangdong Medical Science and Technology Research Fund Project (A2021058).

\section{AUTHORS'CONTRIBUTIONS}

HJS and AMH conceived and designed the study. AMH and HJS and acquired the data. HJS, RXY and AMH analyzed and interpreted the data. HJS and RXY drafted the manuscript. AMH and JZZ critically revised the manuscript for valuable intellectual content. AMH, HJS and JHC performed statistical analysis. All authors read and approved the final manuscript.

\section{ACKNOWLEDGEMENTS}

We are thankful to the Laboratory of Computational Physiology at the Massachusetts Institute of Technology and the elCU Research Institute, Boston Medical Center in the United States, and Beth Israel Deaconess Medical Center for providing the data used in this research.

MATERIAL AND CORRESPONDENCE

Correspondence and requests for materials should be addressed to An-Min Hu for questions.

An-Min $\mathrm{Hu}$

anmin.edu@gmail.com

Department of Anesthesiology, Shenzhen People's Hospital, 1017 Dongmen North Road, Shenzhen, Guangdong 518020, CN +86(0755) 22948275

\section{References}

1. Meagher DJ, Leonard M, Fau - Donnelly S, Donnelly S, Fau - Conroy M, Conroy M, Fau - Adamis D, Adamis D, Fau Trzepacz PT, Trzepacz PT. A longitudinal study of motor subtypes in delirium: relationship with other phenomenology, etiology, medication exposure and prognosis. (1879-1360 (Electronic)).

2. Ely EW, Inouye Sk Fau - Bernard GR, Fau - Gordon BG, Gordon S, Fau - Francis S, Francis J, Fau - May J, May L, Fau Truman L, Truman B, Fau - B, Speroff T, Speroff T, Fau - Gautam S, Gautam S. Fau - Margolin R, Margolin R Fau - Hart RP et al: Delirium in mechanically ventilated patients: validity and reliability of the confusion assessment method for the intensive care unit (CAM-ICU). (0098-7484 (Print)).

3. Bergeron N, Dubois Mj Fau - Dumont M, Dumont M, Fau - Dial S, Dial S, Fau - Skrobik Y, Skrobik Y. Intensive Care Delirium Screening Checklist: evaluation of a new screening tool. (0342-4642 (Print)).

4. Gupta N, de Jonghe J, Schieveld J, Leonard M, Meagher D: Delirium phenomenology: what can we learn from the symptoms of delirium? Journal of psychosomatic research 2008, 65(3):215-222 \%@ 0022-3999.

5. Leslie DL, Marcantonio Er Fau - Zhang Y, Zhang Y, Fau - Leo-Summers L, Leo-Summers L. Fau - Inouye SK, Inouye SK: Oneyear health care costs associated with delirium in the elderly population. (0003-9926 (Print)).

6. Pronovost PJ, Goeschel Ca Fau - Wachter RM, Wachter RM. The wisdom and justice of not paying for "preventable complications". (1538-3598 (Electronic)).

7. Martin J, Franck M, Fau - Fischer M, Fischer M, Fau - Spies C, Spies C. Sedation and analgesia in German intensive care units: how is it done in reality? Results of a patient-based survey of analgesia and sedation. (0342-4642 (Print)).

8. Rhoney DH, Murry KR. National survey of the use of sedating drugs, neuromuscular blocking agents, and reversal agents in the intensive care unit. (0885-0666 (Print)).

9. Bucknall TK, Manias E, Fau - Presneill JJ, Presneill JJ. A randomized trial of protocol-directed sedation management for mechanical ventilation in an Australian intensive care unit. (1530-0293 (Electronic)). 
10. Devlin JW, Skrobik Y, Gelinas C, Needham DM, Slooter AJC, Pandharipande PP, Watson PL, Weinhouse GL, Nunnally ME, Rochwerg B, et al. Clinical Practice Guidelines for the Prevention and Management of Pain, Agitation/Sedation, Delirium, Immobility, and Sleep Disruption in Adult Patients in the ICU. Crit Care Med. 2018;46(9):e825-73.

11. Johnson AE, Pollard TJ, Shen L, Lehman LW, Feng M, Ghassemi M, Moody B, Szolovits PA-O, Celi LA, Mark RA-O: MIMIC-III, a freely accessible critical care database. (2052-4463 (Electronic)).

12. Johnson A, Bulgarelli L, Pollard T, Horng S, Celi LA, Mark IV R: Mimic-iv (version 0.4). PhysioNet 2020.

13. Pollard TJ, Johnson AA-O, Raffa JD, Celi LA, Mark RA-O, Badawi O. The elCU Collaborative Research Database, a freely available multi-center database for critical care research. (2052-4463 (Electronic)).

14. Knaus WA, Wagner Dp Fau - Draper EA, Draper Ea Fau - Zimmerman JE, Zimmerman Je Fau - Bergner M, Bergner M Fau Bastos PG, Bastos Pg Fau - Sirio CA, Sirio Ca Fau - Murphy DJ, Murphy Dj Fau - Lotring T, Lotring T, Fau - Damiano A, Damiano A, et al: The APACHE III prognostic system. Risk prediction of hospital mortality for critically ill hospitalized adults. (0012-3692 (Print)).

15. Stuart EA, King G, Imai K, Ho D: Matchlt: nonparametric preprocessing for parametric causal inference. Journal of statisticalsoftware\%@1548-76602011.

16. Van Buuren S, Groothuis-Oudshoorn K: mice: Multivariate imputation by chained equations in R. Journal of statistical software2011,45(1):1-67\%@1548-7660.

17. Cui Y, Li G, Cao R, Luan L, Kla KM. The effect of perioperative anesthetics for prevention of postoperative delirium on general anesthesia: A network meta-analysis. (1873-4529 (Electronic)).

18. Zhou S, Deng F, Fau - Zhang J, Zhang J, Fau - Chen G, Chen G. Incidence and risk factors for postoperative delirium after liver transplantation: a systematic review and meta-analysis. (2284-0729 (Electronic)).

19. Casault CA-O, Soo A, Lee CH, Couillard P, Niven D, Stelfox T, Fiest KA-O: Sedation strategy and ICU delirium: a multicentre, population-based propensity score-matched cohort study. (2044-6055 (Electronic)).

20. Zaal IJ, Devlin JW, Hazelbag M, Klein Klouwenberg PM, van der Kooi AW, Ong DS, Cremer OL, Groenwold RH, Slooter AJ. Benzodiazepine-associated delirium in critically ill adults. (1432-1238 (Electronic)).

21. Van Der Mast RC: Delirium: the underlying pathophysiological mechanisms and the need for clinical research. Journal of psychosomatic research 1996, 41(2):109-113\%@ 0022-3999.

22. van der Mast RC: Pathophysiology of delirium. Journal of geriatric psychiatry and neurology 1998, 11(3):138-145 \%@ 0891-9887.

23. Pandharipande $P$, Ely EW. Sedative and analgesic medications: risk factors for delirium and sleep disturbances in the critically ill. (0749-0704 (Print)).

24. Gaudreau JD, Gagnon P. Psychotogenic drugs and delirium pathogenesis: the central role of the thalamus. (0306-9877 (Print)).

25. Weinhouse GL, Watson PL. Sedation and sleep disturbances in the ICU. (1557-8232 (Electronic)).

26. Bourne RS, Mills GH. Sleep disruption in critically ill patients-pharmacological considerations. (0003-2409 (Print)).

27. Gile J, Scott B, Fau - Eckle T, Eckle T. The Period 2 Enhancer Nobiletin as Novel Therapy in Murine Models of Circadian Disruption Resembling Delirium. (1530-0293 (Electronic)).

28. Maldonado JR. Pathoetiological model of delirium: a comprehensive understanding of the neurobiology of delirium and an evidence-based approach to prevention and treatment. (0749-0704 (Print)).

29. Brainard J, Gobel M, Fau - Scott B, Scott B, Fau - Koeppen M, Koeppen M, Fau - Eckle T, Eckle T. Health implications of disrupted circadian rhythms and the potential for daylight as therapy. (1528-1175 (Electronic)).

30. Smith HAB, Gangopadhyay M, Fau - Goben CM, Goben Cm Fau - Jacobowski NL. Jacobowski NI Fau - Chestnut MH, Chestnut Mh Fau - Thompson JL, Thompson JI Fau - Chandrasekhar R, Chandrasekhar R Fau - Williams SR, Williams Sr Fau - Griffith K, Griffith K Fau - Ely EW, Ely Ew Fau - Fuchs DC et al: Delirium and Benzodiazepines Associated With Prolonged ICU Stay in Critically III Infants and Young Children. (1530-0293 (Electronic)). 
31. Lonardo NW, Mone Mc Fau - Nirula R, Nirula R, Fau - Kimball EJ, Kimball Ej Fau - Ludwig K, Ludwig K Fau - Zhou X, Zhou X Fau - Sauer BC, Sauer Bc Fau - Nechodom K, Nechodom K Fau - Teng C, Teng C Fau - Barton RG, Barton RG. Propofol is associated with favorable outcomes compared with benzodiazepines in ventilated intensive care unit patients. (15354970 (Electronic)).

32. McNicoll L, Pisani Ma Fau - Zhang Y, Zhang Y, Fau - Ely EW. Ely Ew Fau - Siegel MD, Siegel Md Fau - Inouye SK, Inouye SK: Delirium in the intensive care unit: occurrence and clinical course in older patients. (0002-8614 (Print)).

33. Ely EW, Siegel Md Fau - Inouye SK, Inouye SK. Delirium in the intensive care unit: an under-recognized syndrome of organ dysfunction. (1069-3424 (Print)).

34. Pisani MA, Murphy Te Fau - Van Ness PH. Van Ness Ph Fau - Araujo KLB, Araujo KI Fau - Inouye SK, Inouye SK: Characteristics associated with delirium in older patients in a medical intensive care unit. (0003-9926 (Print)).

35. Pisani MA. Kong Sy Fau - KasI SV, KasI Sv Fau - Murphy TE, Murphy Te Fau - Araujo KLB, Araujo KI Fau - Van Ness PH, Van Ness PH: Days of delirium are associated with 1-year mortality in an older intensive care unit population. (1535-4970 (Electronic)).

36. Ely EW, Shintani A, Fau - Truman B, Truman B, Fau - Speroff T, Speroff T, Fau - Gordon SM, Gordon Sm Fau - Harrell FE, Jr, Harrell Fe Jr Fau - Inouye SK, Inouye Sk Fau - Bernard GR, Bernard Gr Fau - Dittus RS, Dittus RS. Delirium as a predictor of mortality in mechanically ventilated patients in the intensive care unit. (1538-3598 (Electronic)).

37. Jackson JC, Gordon SM, Girard TD, Thomason JWW, Pun BT, Dunn J, Canonico AE, Light RW, Shintani AK, Thompson JL. Delirium as a risk factor for long term cognitive impairment in mechanically ventilated ICU survivors. Am J Respir Crit Care Med. 2007;175:A22.

38. Nelson JE, Tandon N, Fau - Mercado AF. Mercado Af Fau - Camhi SL, Camhi SI Fau - Ely EW, Ely Ew Fau - Morrison RS, Morrison RS: Brain dysfunction: another burden for the chronically critically ill. (0003-9926 (Print)).

\section{Tables}

TABLE 1 | Baseline characteristics of the patients. 
Clinical

Variable*
Baseline covariates of patient

before Propensity Matching
Baseline covariates of patient after Propensity Matching

$\underset{(\mathrm{N}=4,808)}{\operatorname{Midazolam}} \underset{\substack{\text { Midazolam } \\(\mathrm{N}=73,556)}}{\mathrm{No}} \mathrm{SD}^{\#} \quad P$ value $\quad \underset{(\mathrm{N}=4,674)}{\text { Midazolam }} \underset{\substack{\text { Midazolam } \\(\mathrm{N}=4,674)}}{\text { No }}$ SD $\quad P$ value

Age, No. (\%)

\begin{tabular}{|c|c|c|c|c|c|c|c|c|}
\hline $\begin{array}{l}18 \text { to } 45 \\
\text { years }\end{array}$ & 945 (19.7) & $9582(13)$ & 0.261 & $<0.001$ & $\begin{array}{l}1018 \\
(18.7)\end{array}$ & 767 (19.7) & 0.033 & 0.65 \\
\hline $\begin{array}{l}46 \text { to } 65 \\
\text { years }\end{array}$ & 1876 (39) & $\begin{array}{l}25641 \\
(34.9)\end{array}$ & & & $\begin{array}{l}2164 \\
(39.7)\end{array}$ & $\begin{array}{l}1527 \\
(39.2)\end{array}$ & & \\
\hline $\begin{array}{l}66 \text { to } 80 \\
\text { years }\end{array}$ & $\begin{array}{l}1404 \\
(29.2)\end{array}$ & $\begin{array}{l}24495 \\
(33.3)\end{array}$ & & & $\begin{array}{l}1644 \\
(30.1)\end{array}$ & $\begin{array}{l}1073 \\
(27.6)\end{array}$ & & \\
\hline $\begin{array}{l}81 \text { to } 89 \\
\text { years }\end{array}$ & $458(9.5)$ & $\begin{array}{l}10342 \\
(14.1)\end{array}$ & & & $500(9.2)$ & 409 (10.5) & & \\
\hline $\begin{array}{l}\text { over } 89 \\
\text { years }\end{array}$ & $125(2.6)$ & 3496 (4.8) & & & $129(2.4)$ & $117(3)$ & & \\
\hline $\begin{array}{l}\text { Female, No. } \\
(\%)\end{array}$ & $\begin{array}{l}2002 \\
(41.6)\end{array}$ & $\begin{array}{l}33697 \\
(45.8)\end{array}$ & 0.084 & $<0.001$ & $\begin{array}{l}2206 \\
(40.4)\end{array}$ & $\begin{array}{l}1701 \\
(43.7)\end{array}$ & 0.002 & 0.933 \\
\hline
\end{tabular}

Ethnicity, No.

(\%)

\begin{tabular}{|c|c|c|c|c|c|c|c|c|}
\hline White & $\begin{array}{l}2940 \\
(61.1)\end{array}$ & $\begin{array}{l}50421 \\
(68.5)\end{array}$ & 0.272 & $<0.001$ & $\begin{array}{l}3286 \\
(60.2)\end{array}$ & $\begin{array}{l}2488 \\
(63.9)\end{array}$ & 0.016 & 0.964 \\
\hline Black & $542(11.3)$ & 9572 (13) & & & $596(10.9)$ & $453(11.6)$ & & \\
\hline Latino & 173 (3.6) & $3253(4.4)$ & & & 199 (3.6) & 146 (3.8) & & \\
\hline Asian & $121(2.5)$ & $1850(2.5)$ & & & 143 (2.6) & $98(2.5)$ & & \\
\hline Other & $\begin{array}{l}1032 \\
(21.5)\end{array}$ & 8460 (11.5) & & & $\begin{array}{l}1231 \\
(22.6)\end{array}$ & 708 (18.2) & & \\
\hline $\begin{array}{l}\text { APACHE-III } \\
\text { score }\end{array}$ & $51(36-72)$ & $38(28-52)$ & 0.595 & $<0.001$ & $51(36-74)$ & $47(34-67)$ & 0.035 & 0.087 \\
\hline $\begin{array}{l}\text { Glasgow } \\
\text { Coma Scale }\end{array}$ & $15(13-15)$ & $\begin{array}{l}13.2(13- \\
15)\end{array}$ & 0.003 & 0.812 & $15(14-15)$ & $14(13-15)$ & 0.003 & 0.866 \\
\hline $\begin{array}{l}\text { Mean Blood } \\
\text { Pressure, } \\
\text { mmHg }\end{array}$ & $\begin{array}{l}80.3(71.3- \\
91.7)\end{array}$ & $\begin{array}{l}85.4(75.3- \\
93.5)\end{array}$ & 0.193 & $<0.001$ & $\begin{array}{l}78.3(70.3- \\
88.7)\end{array}$ & $\begin{array}{l}84.7 \text { (74.7- } \\
95.3)\end{array}$ & 0.002 & 0.919 \\
\hline $\begin{array}{l}\text { Respiratory } \\
\text { Rate, Beat Per } \\
\text { Minute }\end{array}$ & $19(16-23)$ & $\begin{array}{l}19(16.5- \\
22)\end{array}$ & 0.063 & $<0.001$ & $19(16-22)$ & $\begin{array}{l}19.4(16.5- \\
22.9)\end{array}$ & 0.016 & 0.433 \\
\hline $\begin{array}{l}\text { Urine volume, } \\
\mathrm{ml} / \mathrm{kg} / \text { hour }\end{array}$ & $\begin{array}{l}1.1 \\
1.5)\end{array}$ & $\begin{array}{l}1.1(0.7- \\
1.5)^{(0 .}\end{array}$ & 0.002 & 0.9 & $\begin{array}{l}1.1(0.7- \\
1.5)\end{array}$ & $\begin{array}{l}1.1(0.7- \\
1.5)^{(0 .}\end{array}$ & 0.012 & 0.553 \\
\hline $\begin{array}{l}\text { Hemoglobin, } \\
\text { g/dL }\end{array}$ & $\begin{array}{l}10.7(9- \\
11.7)\end{array}$ & $\begin{array}{l}10.9(9.7- \\
11.8)\end{array}$ & 0.169 & $<0.001$ & $\begin{array}{l}10.5(9- \\
11.6)\end{array}$ & $\begin{array}{l}10.9(9.3- \\
11.6)^{(9-}\end{array}$ & 0.005 & 0.793 \\
\hline $\begin{array}{l}\text { White Blood } \\
\text { Cell, k/ } \mu \mathrm{L}\end{array}$ & $\begin{array}{l}11.6(8.1- \\
15.2)\end{array}$ & $\begin{array}{l}11.3(8.7- \\
13.7)\end{array}$ & 0.086 & $<0.001$ & $\begin{array}{l}12(8.7- \\
15.9)\end{array}$ & $\begin{array}{l}11.1(8.1- \\
13.8)\end{array}$ & 0.009 & 0.655 \\
\hline $\begin{array}{l}\text { Alanine } \\
\text { transaminase, } \\
\text { IU/L }\end{array}$ & $\begin{array}{l}67.9(23- \\
100.9)\end{array}$ & $\begin{array}{l}74.1(26- \\
96.8)\end{array}$ & 0.095 & $<0.001$ & $\begin{array}{l}68.3(22- \\
100.4)\end{array}$ & $\begin{array}{l}75.7(26- \\
104.9)\end{array}$ & 0.008 & 0.696 \\
\hline Glutamic & 90.6 (33- & 99.3 (31- & 0.112 & $<0.001$ & 90 (33- & 101 (37- & 0.012 & 0.566 \\
\hline
\end{tabular}




\begin{tabular}{|c|c|c|c|c|c|c|c|c|}
\hline $\begin{array}{l}\text { Oxaloacetic } \\
\text { Transaminase, } \\
\text { IU/L }\end{array}$ & 144.1) & 136.8) & & & 142.8) & 147.1) & & \\
\hline Albumin, $\mathrm{g} / \mathrm{dL}$ & $\begin{array}{l}3.1(2.8- \\
3.4)\end{array}$ & $3.3(3-3.5)$ & 0.265 & $<0.001$ & $\begin{array}{l}3.1(2.8- \\
3.4)\end{array}$ & $\begin{array}{l}3.2(2.9- \\
3.4)\end{array}$ & 0.028 & 0.181 \\
\hline $\begin{array}{l}\text { Blood Urea } \\
\text { Nitrogen, } \\
\text { mg/dL }\end{array}$ & $21(13-34)$ & $20(15-29)$ & 0.093 & $<0.001$ & $\begin{array}{l}20.9(14- \\
33.6)\end{array}$ & $21(14-31)$ & 0.015 & 0.458 \\
\hline $\begin{array}{l}\text { Creatinine, } \\
\mathrm{mg} / \mathrm{dL}\end{array}$ & $1(0.7-1.6)$ & $\begin{array}{l}1.1(0.8- \\
1.4)\end{array}$ & 0.029 & 0.052 & $1(0.7-1.6)$ & $\begin{array}{l}1.1(0.7- \\
1.5)\end{array}$ & 0.02 & 0.322 \\
\hline $\begin{array}{l}\text { Lactate, } \\
\mathrm{mg} / \mathrm{dL}\end{array}$ & $\begin{array}{l}1.7(1.3- \\
2.1)^{-}\end{array}$ & $\begin{array}{l}1.8(1.5- \\
2.2)\end{array}$ & 0.019 & 0.136 & $\begin{array}{l}1.7(1.3- \\
2.2)\end{array}$ & $\begin{array}{l}1.7(1.4- \\
2.1)\end{array}$ & 0.016 & 0.427 \\
\hline $\begin{array}{l}\text { Oxgenation } \\
\text { index }\end{array}$ & $\begin{array}{l}54.7(50- \\
60.4)\end{array}$ & $\begin{array}{l}51.9(50.6- \\
57.3)\end{array}$ & 0.717 & $<0.001$ & $\begin{array}{l}53.9(50- \\
60)\end{array}$ & $\begin{array}{l}55.9(50.8- \\
60.9)\end{array}$ & 0.045 & 0.03 \\
\hline $\begin{array}{l}\text { Mechanical } \\
\text { ventilation, } \\
\text { No. (\%) }\end{array}$ & $\begin{array}{l}3134 \\
(65.2)\end{array}$ & $\begin{array}{l}13534 \\
(18.4)\end{array}$ & 1.077 & $<0.001$ & $\begin{array}{l}4452 \\
(81.6)\end{array}$ & $\begin{array}{l}1500 \\
(38.5)\end{array}$ & 0.021 & 0.312 \\
\hline
\end{tabular}

\section{ICU type, No.}

(\%)

\begin{tabular}{|c|c|c|c|c|c|c|c|}
\hline SICU & $227(4.7)$ & 3462 (4.7) & 0.399 & $<0.001$ & $213(3.9)$ & $230(5.9)$ & 0.065 \\
\hline $\mathrm{CCU}$ & $126(2.6)$ & $6678(9.1)$ & & & $112(2.1)$ & 107 (2.7) & \\
\hline NICU & $10(0.2)$ & $3000(4.1)$ & & & $7(0.1)$ & $5(0.1)$ & \\
\hline Others & $\begin{array}{l}4445 \\
(92.5)\end{array}$ & $\begin{array}{l}60416 \\
(82.1)\end{array}$ & & & $\begin{array}{l}5123 \\
(93.9)\end{array}$ & $\begin{array}{l}3551 \\
(91.2)\end{array}$ & \\
\hline
\end{tabular}

\section{Number of}

beds, No. (\%)

\begin{tabular}{|c|c|c|c|c|c|c|c|c|}
\hline$<100$ & $0(0)$ & $470(0.6)$ & 0.508 & $<0.001$ & $0(0)$ & $0(0)$ & 0.073 & 0.002 \\
\hline $100-249$ & $74(1.5)$ & 5477 (7.4) & & & $55(1)$ & 65 (1.7) & & \\
\hline $250-499$ & $85(1.8)$ & 7762 (10.6) & & & $55(1)$ & $87(2.2)$ & & \\
\hline$\geq 500$ & $\begin{array}{l}4649 \\
(96.7)\end{array}$ & $\begin{array}{l}59847 \\
(81.4)\end{array}$ & & & $5345(98)$ & $\begin{array}{l}3741 \\
(96.1)\end{array}$ & & \\
\hline $\begin{array}{l}\text { Teaching, No. } \\
(\%)\end{array}$ & $\begin{array}{l}4586 \\
(95.4)\end{array}$ & $\begin{array}{l}56129 \\
(76.3)\end{array}$ & 0.569 & $<0.001$ & $\begin{array}{l}5268 \\
(96.6)\end{array}$ & $\begin{array}{l}3703 \\
(95.1)\end{array}$ & 0.073 & 0.001 \\
\hline
\end{tabular}

Abbreviations: AaDO2, alveolar-arterial oxygen difference; APACHE-III score, the acute physiology and chronic health evaluation III score; CCU, cardiac care unit; Dex, dexmedetomidine; NICU, neurological intensive care unit; SICU, surgical intensive care unit.

* Data shown as mean \pm standard deviation, number (percent), or median (interquartile range) as appropriate.

\# SD = standardized difference ( $S D \geq 0.1$ represent significant differences in covariables between groups).

Table2. Results of Propensity-Matched and Multivariate Analysis in Patients with Midazolam Treated 


\begin{tabular}{llllllll} 
& \multicolumn{2}{l}{ Propensity } & matched analysis $(\mathrm{N}=9,348)$ & \multicolumn{3}{l}{ Multivariable analysis $(\mathrm{N}=78,364)$} \\
\cline { 2 - 8 } & Estimate & $95 \% \mathrm{Cl}$ & $P$ Value & Estimate & $95 \% \mathrm{Cl}$ & $P$ Value \\
\hline Odds of delirium, OR & 2.54 & 2.31 to 2.79 & $<0.001$ & 3.04 & 2.83 to 3.26 & $<0.001$ \\
\hline Odds of mortality, OR & 1.33 & 1.17 to 1.52 & $<0.001$ & 1.30 & 1.18 to 1.43 & $<0.001$ \\
\hline Difference in ICU days & 0.37 & 0.29 to 0.45 & $<0.001$ & 0.54 & 0.50 to 0.57 & $<0.001$ \\
\hline Difference in hospital days & -0.35 & -0.66 to -0.04 & 0.03 & -0.03 & -0.30 to 0.23 & 0.81 \\
\hline Odds of discharge to home, OR & 0.81 & 0.74 to 0.89 & $<0.001$ & 0.79 & 0.73 to 0.84 & $<0.001$ \\
\hline
\end{tabular}

Abbreviation: $\mathrm{OR}$, odds ratio; $\mathrm{Cl}, \mathrm{confidence} \mathrm{interval.}$

\section{Supplementary Files}

This is a list of supplementary files associated with this preprint. Click to download.

- EquatorChecklist.docx 